\title{
A fully general index of political competition
}

\author{
Bernard Grofman ${ }^{\mathrm{a}, *}$, Peter Selb ${ }^{\mathrm{b}, 1}$ \\ a Department of Political Science and Center for the Study of Democracy, University of Caiifornia, Irvine, CA 92697-5100, USA \\ ${ }^{b}$ Fachbereich Politik and Verwaltungswissenschaft, Universität Konstanz, Universitätstrase 10, D-78457 Konstanz, Postfach D85, Germany
}

A R T ICLE I N F O

\section{Keywords:}

Voter turnout

Political competition

Electoral rules

Proportional representation

Threshold of Exclusion

\begin{abstract}
A B S T R A C T
As Selb /A deeper look at the proportionality-turnout nexus. Comparative Political Studies, forthcoming] observes, the standard measure of (posterior) competitiveness in elections used in plurality contests, namely the difference between the winner and the second place finisher, has no "self-evident counterpart in multi-member PR districts". Following lines similar to Taagepera and Grofman [2003. Mapping the indices of seats-votes disproportionality and inter-election volatility. Party Politics 9, 659-677] we identify six properties that any index of competition should satisfy and then offer a new measure that satisfies all six properties which is applicable to virtually any electoral rule. We then apply our new and more fully general index of political competition to data from PR elections in Switzerland to see the extent to which the index of competition is correlated with levels of voter turnout.
\end{abstract}

\section{Introduction}

As Selb (forthcoming) observes, the standard measure of (posterior) competitiveness in elections used in plurality contests, namely the difference between the winner and the second place finisher, has no "self-evident counterpart in multi-member PR districts". ${ }^{2}$ For PR elections under quota rules such as d'Hondt and Sainte-Laguë, Selb (forthcoming) proposes, to use the weighted gap between the electoral quotient of the party winning the $m$ th and final

\footnotetext{
If Initially presented at the Annual Meeting of the European Public Choice Society. Jena, Germany. The first-named author is indebted for research support to the Jack W. Peltason (Bren Foundation) Endowed Chair and to the Social Sciences and Humanities Research Council of Canada (SSHRCC) Grant \#410-2007-2153, to study "Political Competition" (co-PIs: Stanley Winer, and J. Stephen Ferris). We are both indebted to Sue Ludeman and Clover Behrend-Gethard for bibliographic assistance.

* Corresponding author. Tel. +1 949824 6394; fax: + 19498248762. E-mail addresses: bgrofman@uci.edu (B. Grofman), peter.selb@unikonstanz.de (P. Selb).

1 Tel.: +49753188 2321; fax: +497531 884482 .

2 A preliminary version of this paper has been presented at the First World Congress of Public Choice, Amsterdam, March 29-April 1, 2007.
}

seat and the electoral quotient of the closest loser as a measure of competitiveness. This measure seems a natural generalization of what is commonly done for the single seat case. However, there are other ways to generalize the measure of competitiveness used in plurality elections. Following lines similar to Taagepera and Grofman (2003) we identify six properties that any index of competition should satisfy, and then offer a new measure that satisfies all six properties which is applicable to virtually any electoral rule. By contrast, for example, the Selb (forthcoming) measure satisfies only two of these six properties.

We believe any measure of competitiveness should have the following properties:

(1) The measure should be party-specific, i.e., it should allow for the possibility that voters of different parties might have different incentives to turn out to vote.

(2) For each party, the measure should run from zero to 1 ; with 0 indicating situations where voter incentives to 
turn out are least, and 1 indicating situations where voters incentives to turn out are greatest. ${ }^{3}$

(3) The measure should be summable over all parties to give a weighted average of overall incentives for turnout in a given district. This aggregate measure should, when appropriately normalized, still run from zero to 1 ; with 0 again indicating situations where, in the aggregate, voter incentives to turn out are least, and 1 indicating situations where, in the aggregate, voter incentives to turn out are greatest. ${ }^{4}$ The weights should reflect the vote shares of the parties, and aggregation to the legislature as a whole should not be distorted by variation in district population size as a function of district magnitude, $m$.

(4) For each party, the maximum value should obtain if the votes required by that party to win its last seat(s) is such that a vote loss of one vote would convert a win for that seat (those seats) into a loss. ${ }^{5}$ The minimum value should obtain if one candidate/party receives all the votes.

(5) The measure should be sensitive to the nature of the voting rule being used. In particular, we propose that it should vary with the Threshold of Exclusion of that rule.

(6) For two-candidate plurality elections, the measure should reduce to a simple function of the difference in vote share between the winner and the loser.

These six properties are all intuitively reasonable ones, but the underlying theory that undergirds them is one that is neo-Downsian in character in that we take incentives for turnout to be related to the likelihood that blocs of voters might be pivotal. The smaller the bloc of voters that needs to changes its votes to affect the outcomes for any given party, either to make it better off or to make it worse off, the greater the incentives for members of that party to turn out to vote, either to keep what they have or to make additional gains. And the greater the incentives of party leaders to pour resources into mobilization efforts. Nonetheless, although there are neo-Downsian ideas that inspired the authors to develop this measure of competition, even if one is not sympathetic to the rational choice idea of pivotal (bloc) voting power that we draw upon, the measure of competition that we propose still has very attractive properties for any one interested in measuring competitiveness in a comparable way across different

\footnotetext{
${ }^{3}$ of course, we could just as easily have rescaled so as to create a measure running from, say. minus infinity to plus infinity. The point is simply to have a metric that has an intuitively interpretable meaning.

4 See previous footnote.

5 The possible plural is inserted here to allow us to deal with methods such as plurality bloc voting with party-line voting. where a switch in votes might affect multiple seats at once.
}

electoral rules and across different party and party strength settings. ${ }^{6}$

We will illustrate our ideas about how to measure competitiveness in a fully general way applicable to multiseat multiparty contests and not just two party competition with the three party five seat d'Hondt list PR example used by Selb (forthcoming). The example is shown in Table 1 (along with the relevant divisor quotients). This example looks at competition within a single election but, in principle, the concept we propose can be used to develop more aggregated measures of mean competition or range of competition over time or among or across cases.

Let us first look at turnout incentives from the standpoint of Party $C^{7}$ Here, there are two cases that need to be investigated. On the one hand, supporters of Party $C$ might be concerned to turn out in order to increase the likelihood that Party $C$ would pick up a second seat; on the other hand. supporters of party $C$ might be concerned to turn out in order to insure that Party $\mathrm{C}$ does not lose the seat it already

\footnotetext{
6 The (neo-)Downsian approach Riker,W., Ordeshook, P., 1968. A theory of the calculus of voting. American Political Science Review 62. 25-42 has both defenders and opponents. With respect to turnout the latter have argued, in Morris Fiorina's apt metaphor, that "turnout is the paradox that ate rational choice theory" (quoted in Grofman. 1993). This is not a view the present authors share. There have been a number of attempted syntheses of rational choice ideas and other approaches designed to sidestep the problem that, viewed purely instrumentally and purely as a matter for individual decisions, voting is a costly and often irrational act. For example, Grofman (1993) takes the view that rational choice approaches to tumout deal best with explaining differences in turnout across elections as a function of election type, electoral competitiveness, candidate differences, etc., i.e., in terms of what economists call a "comparative statics" approach. In this view trying to explain why someone votes is tantamount to explaining why someone goes to baseball games; what rational choice models can do is help explain how the levels of turnout at ball parks might vary as we change the prices of tickets (relative to other activities that might be substituted for a day/ night at the old ball game). Franklin (2004: 31 ) also builds on the insight that we should try to explain turnout variations across elections but looks as well at turnout variation as across groups of people (e.g., generational cohorts) and over time (see also Hanks and Grofman, 1998). He integrates in to a rational choice model the notion that "citizens are socialized into the habit of voting or not voting during their first elections" (Franklin, 2004: 32). Clarke et al. (2004, chapters 7-8) identify two broad approaches: sociological and rational choice, with the former divided into three models (perceived equity/fairness, social capital and civic voluntarism) and the latter approach also divided into three models (cognitive mobilization, minimalist, and general incentives). It is the second of these latter approaches that is closest to the approach commonly attributed to Downs (1957), but Clarke et al, do not require that instrument incentives be based on a purely individualistic calculus. Clarke et al provide a number of comparisons of the empirical power of the various models they describe. Other important recent theoretical and empirical work on turnout has been done by Andre Blais (Blais, 2006; Blais and Aarts, 2006; Blais et al., 2000). Here, however, we do not need to adjudicate among competing approaches to explaining turnout, since our answers to the specific problem we are interested in solving, namely developing a full general measure of competition, does not really depend upon how we think about turnout, although we certainly would hope that, empirically. the measure we offer would be related to turnout (see below).

${ }^{7}$ Note that we are deliberately expressing incentives for turnout as linked to party incentives to mobilize voters. Following Jacobson (1983): see also Cox, 1999), we think that this is the most plausible explanation for the turnout-competition linkage. However, the approach to competitiveness we offer also applies if we believe, a la Downs (1957), that voter perceptions of the likelihood that their votes might change outcomes affects the probability that they will go to the polls.
} 
Table 1

Example used by Selb (forthcoming). Table 2. Three parties, five seats to be filled, calculations for the d'Hondt method.

\begin{tabular}{llll}
\hline Divisor & Party A & Party B & Party C \\
\hline 1 & $0.53(1)$ & $0.30(2)$ & $0.17(5)$ \\
2 & $0.27(3)$ & 0.15 & 0.08 \\
3 & $0.18(4)$ & & \\
4 & 0.13 & & \\
\hline
\end{tabular}

Note: Ranks in parentheses indicate seats won.

has. Both for purposes of calculating seat loss and for purposes of calculating seat gain, we shall use the respective worst case scenarios to calculate the incentive for turnout.

For Party $C$ to be sure to gain a second seat it would need to gain an additional 16.34 percentage points of vote share; since no matter how the accompanying vote loss is distributed among the remaining two parties, Party $C$ is still guaranteed two seats (since $0.3334 / 2>0.6663 / 4$ ). While there are scenarios in which Party $C$ could gain a seat with an even lower vote share gain, these lower percentages do not guarantee a second seat.

For Party $C$ to lose its only seat taking the present distribution of vote shares for other parties as fixed, it would need to lose only 2 + percentage points of vote share, since that would bring it below the vote share level of the highest losing quotient of 0.15 (see the second entry in the Party B column). However, for Party $C$ to lose a seat under the worst case scenario - one in which any vote share it lost would go to Party B - a loss of just over 1.33 percentage points of its vote share would result in a lost seat, since the solution to $(0.30+x) / 2=0.17-x$ is given by $x=.0133$.

How shall we characterize the magnitude of Party C's incentives to turn out supporters? Well, under d'Hondt, for each $1 / 6+$ vote share a party can guarantee an additional seat, ${ }^{8}$ i.e., $1 /(m+1)=1 / 6=0.1667$ is the Threshold of Exclu$\operatorname{sion}\left(T^{E}\right)$ for a d'Hondt voting rule with $m=5$ (see Rae et al., 1971). It thus seems to us to be "natural" to initially "normalize" values of our index of competition by the Threshold of Exclusion since a gain (loss) of one Threshold of Exclusion percentage point share of votes will always give rise to the possibility of a gain (loss) of one seat, and thus provides an upper bound on the magnitude of the vote share shift than could change outcomes plus or minus one seat.

We will use whichever of the gain and loss calculations gives the party the maximum incentive to turn out its supporters. Thus, in this example, we shall take the incentive for Party $C$ to mobilize its supporters to turn out as

$$
\begin{aligned}
& \max [(0.1667-0.1634),(0.1667-0.0133)] / 0.1667 \\
& \quad=0.1567 / 0.1667=0.94
\end{aligned}
$$

Similarly, if Party B were to gain 4+ percentage points this would assure that it win a second seat, regardless of how that seat loss is distributed between the other parties, since $(0.30+0.04) / 2=0.17$. The worst case scenario for loss occurs if Party B were to lose 13.4 percentage points of its votes to Party $A$, since $(0.53+x) / 4=0.30-x$, when $x=0.134$. It would take a seat loss of 14.3 percentage points of vote share to Party $C$ to cost party $B$ a seat since, when we solve $0.30-x=(0.17+x) / 2$, we obtain $x=0.143$. Thus, the loss to Party A is the worst case scenario for Party B. Hence, we take the incentive for Party B to mobilize it supporters to turn out as

$$
\begin{aligned}
& \max [(0.1667-0.04),(0.1667-0.134)] / 0.1667 \\
& \quad=0.1267 / 0.1667=0.76
\end{aligned}
$$

Similarly, if Party A were to gain 13.4 percentage points this would assure that it win a fourth seat, regardless of how that seat loss is distributed between the other parties, since $(0.53+x) / 4=0.30-x$, when $x=0.134$; while if Party $\mathrm{A}$ were to lose $3+$ percentage points of vote share, that loss would cost it a seat if the loss turned into corresponding gain for party $B$, since, when we solve $(0.53-x) /$ $3=(0.30+x) / 2$, we obtain $x=0.032$. Thus, the incentive for Party A supporters to turn out is given by

$$
\begin{aligned}
& \max [(0.1667-0.134),(0.1667-0.032)] / 0.1667 \\
& \quad \leq 0.1347 / 0.1667=0.81
\end{aligned}
$$

We can make more precise the nature of the calculations reported for the example above by expressing our loss and gain scenarios in straightforward mathematical notation. Here we present results for the d'Hondt formula. ${ }^{9}$

Under d'Hondt the vote share $x^{G}$ needed for party $i$ to be certain to gain another seat if there are $m$ seats is given by

$x_{i}^{G}=\left[\left(s_{i}+1\right) /(m+1)\right]-v_{i}$ if $s_{i}<m$ and $x_{i}^{G}$

$\leq T^{E}$, otherwise not defined

where $s_{i}$ is the number of seats won by party $i, v_{i}$ is party $i$ 's vote share, and the term $\left(s_{i}+1\right) /(m+1)$ is the Threshold of Exclusion for the $(s+1)$ th seat, ${ }^{10}$

For party $i$ to lose its sth and final seat under the worst case scenario, the required vote share is

$$
\left(v_{j}+x^{L}\right) /\left(s_{j}+1\right)=\left(v_{i}-x^{L}\right) / s_{i}
$$

where party $j$ is the runner-up for party $i$ 's final and sth seat. Solving for $x^{L}$ yields

$x_{i}^{L}=\left(-s_{i} v_{j}+s_{i} v_{i}+v_{i}\right) /\left(s_{i}+s_{j}+1\right)$

if $s_{i}>0$, otherwise not defined

\footnotetext{
8 On rare occasions, the maximum vote share required to surely win another seat may be of greater magnitude than $T^{E}$. particularly when a party has won its current seat with a substantially smaller share than the $T^{E}$ for the current seat. However, this scenario is irrelevant for the calculation of the index since that will give essentially zero incentives for turnout to gain seats, so all the action will be in the incentive to turnout to not lose the seat a party has, and the term exceeding $T^{E}$ will drop out of the calculations of overall turnout incentives. See Eq. (4).
}

\footnotetext{
${ }^{9}$ Analogous results can be generated for other parametric divisor rules such as Sainte-Laguë or the Danish method. Coping with non-parametric methods such as modified Sainte-Laguë will be more difficult, though.

${ }^{10}$ In electoral systems where district-level legal thresholds $\left(T^{t}\right)$ apply. this term should correspond to the legal threshold if $s_{i}=0$ and $T^{2}>T^{\mp}$. Equally. legal thresholds have to be considered when calculating worst case scenarios regarding seat losses.
} 
In general, for party $i$, the incentive for that party's supporters to turn out (given some observed or predicted vote share allocation) can be written as

$c_{i}=\max \left[\left(T^{E}-x_{i}^{G}\right),\left(T^{E}-x_{i}^{L}\right)\right] / T^{E}$

where we express the vote losses and gains in the expression above as fractions of total votes cast.

If we denote the above expression, which we may take to be the Index of Competition for party $i$, as $c_{i}$, then, within any given district the overall Index of Competition, $C$, is simply a weighted average of the competition index values of the individual parties, where the weights are the $v_{i}$ values, i.e., the vote shares of each of the parties. Thus, we may write

$C=\sum_{i=1}^{n} v_{i} \times c_{i}$

For the Selb example shown in Table 1, we can calculate that $C$ equals $0.53 \times 0.81+0.30 \times 0.76+0.17 \times 0.94=0.82$.

\section{Real word examples}

Below we present calculations of the Index of Competition for a set of real world elections: the Swiss National Council elections 1971-2007.11 Switzerland features one of the very few "districted proportional representation" systems where district magnitude varies over the whole range from single seat to large 35-member districts and where eventual disproportionalities emanating from the translation of votes into seats at the district level are not corrected at higher tiers (see Monroe and Rose, 2002). Thus, Swiss National Council elections provide an ideal experimental ground for studying the properties of the competition index. ${ }^{12}$

First, how does $C$ vary with the Threshold of Exclusion? As Cox (1999) argues in his reflections on Downs' decisiontheoretic model of turnout, the intensity of competition should be more variable both over space and time, and therefore lower on average in districts of lower magnitudes, i.e., districts with higher $T^{E}$. A descriptive table that shows means and variances of the key variables is given in Appendix; the Appendix also has a table that reports the bivariate correlations among our variables. As we see, the correlation between our index of competition and $T^{E}$ has the expected negative sign.

\footnotetext{
1 STATA code that implements the index is available from the authors. 12 Switzerland is divided into 26 electoral districts. The observation period includes 10 elections. Some single-member districts held "tacit elections" during the observation period, i.e., no candidate challenging the incumbent was nominated (i.e., non-competitiveness in extremo). Moreover, one district was not established until 1979. Therefore, our panel includes 253 instead of 260 district-year observations. Seats are allocated according to the Hagenbach-Bischoff (a.k.a. Jefferson) method, not d'Hondt. For a proof of equivalence of the Hagenbach-Bischoff and d'Hondt methods, see Gauglhofer (1988). The Swiss electoral system also provides for the opportunity to run joint lists in multi-member districts in order to avoid wasted votes. This may occasionally impact on the allocation of seats. Due to a lack of data, we could only partially account for joint lists. In other instances, we therefore do as if there were no joint lists. Moreover, elections to the federal chamber of the parliament, the Council of States, are simultaneously held in most districts. We will also ignore potential spill-over effects from these elections in our analysis.
}

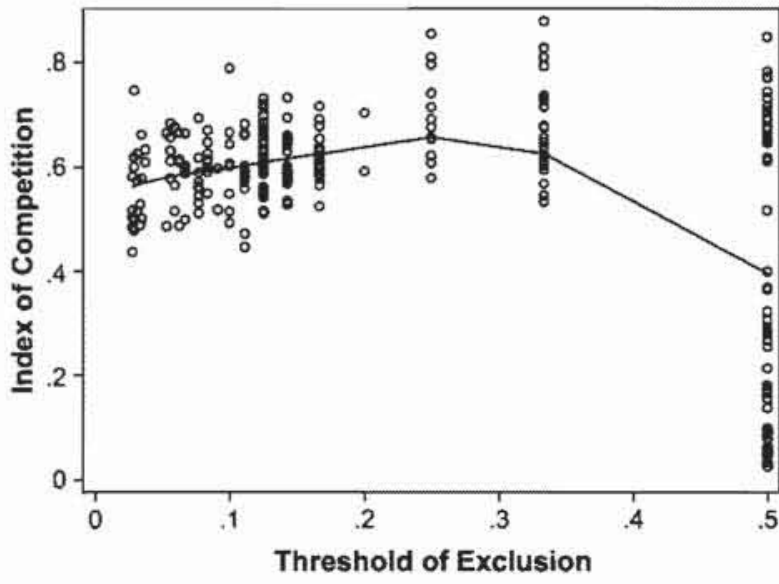

Fig. 1. Index of Competition versus Threshold of Exclusion in Swiss National Council elections, 1971-2007. Note: 253 district-year observations. Line represents locally weighted regression fit.

Fig. 1 plots district-level Index of Competition values versus exclusion thresholds in Swiss National Council elections 1971-2007. This data suggests that the Cox expectation is satisfied: the higher $T^{E}$, the greater the variability of competition, and the lower the average level of competition. Lower $T^{£}$, in turn, seems to guarantee that elections will almost always be competitive at the district level. ${ }^{13}$ However, it is important to check for non-linearities. The Fig. 1 bivariate scatterplot also includes a LOESS line which smooths the data to present a clearer picture. We can see from Fig. 1 that the link between $C$ and $T^{\xi}$, though essentially monotonic, is also nonlinear.

The data shown in Fig. 1 would lead us to expect turnout to be more variable and lower on average with rising $T^{\varepsilon}$. In order to test this conjecture, we set up a simple heterocedastic regression model ${ }^{14}$ where both mean turnout and the (log of the) turnout variance about this mean is a function of $T^{E}$ plus a secular trend as a control variable. ${ }^{15}$ The ML-estimates are reported in Table 2 (Model 1). As expected, $T^{\varepsilon}$ has a highly significant negative effect on mean turnout, and a strong positive effect on turnout variability.

\footnotetext{
13 This expectation goes against that of work by scholars such as Dahl and Tufte (1973) on constituency population effects. which argues that smaller districts (as measured by population) will, ceteris paribus, have higher turnout, since we would expect that districts with a large number of seats (and thus low $T^{\mathcal{E}}$ ) will also be larger in population terms. See also discussion in Latner (unpublished).

14 See, for example, Harvey (1976). The model consists of a mean function: Turnout $=\beta_{0}+\beta_{1} \times T^{E}+\beta_{2} \times$ Trend $+\varepsilon$, and a variance function: $\operatorname{Var}(\varepsilon)=\exp \left(\gamma_{0}+\gamma_{1} \times T^{E}+v\right)$ which can be simultaneously fitted with Maximum Likelihood. We report robust standard errors that account for the panel structure of the data.

15 National-level turnout in Switzerland has declined dramatically from the late 1960 s on, mainly due to an informal agreement among the four largest political parties that codified the composition of the national government in 1959 (an event closely related to the notion of national competition; see footnote 16), and due to the late female enfranchisement in 1971 (see Franklin, 2004). For the time being, we will consider such national-level development as a nuisance in estimating the effects of interest. For the same reason, we have excluded one district where voting is compulsory (Schaffhausen), since compulsory voting presumably distorts the competition-turnout nexus.
} 
Table 2

ML-estimates from the heteroscedastic regression models of district-level turnout in Swiss National Council elections, 1971-2007.

\begin{tabular}{lcc}
\hline & Model 1 & Model 2 \\
\hline Mean function & $0.543^{* * *}(0.024)$ & $0.413^{* * *}(0.033)$ \\
Constant & $-0.188^{* * *}(0.072)$ & $-0.129^{* *}(0.066)$ \\
Threshold of Exclusion & & $0.212^{* * *}(0.035)$ \\
Index of Competition & $-0.009^{* * *}(0.002)$ & $-0.010^{* * *}(0.002)$ \\
Trend & & $-5.258^{* * *}(0.410)$ \\
Variance function & $-5.458^{* * *}(0.417)$ & $-1.065(1.302)$ \\
Constant & $2.326^{*}(1.325)$ & $106.3(4)$ \\
Threshold of Exclusion & $78.3(3)$ & 13 \\
Model $\chi^{2}$ (d.f.) &
\end{tabular}

Note: Robust standard errors in parentheses, 243 district-year observations. ${ }^{\cdots *} p<01$; ${ }^{* * p}<05$ : ${ }^{*} p<10$.

Second and most importantly, does $C$ capture real mobilization and turnout incentives? The bivariate correlation between $C$ and turnout reported in Appendix is, as expected positive and strongly significant. Fig. 2 shows the bivariate scatterplot between $C$ and turnout, and again includes a LOESS line which smooths the data to present a clearer picture. From Fig. 2, we can see that the bivariate link between $C$ and turnout is essentially monotonic and close to linear.

To look at the relationship between $C$ and turnout in more depth we include $C$ into the equation predicting mean turnout in order to check whether unequal levels of competition account for the previously observed pattern of turnout variability (see Table 2, Model 2 ). Indeed, $C$ retains a strong positive impact on turnout, corroborating our expectation that parties' mobilization efforts and voter turnout are highly responsive to political competition, and that a simple posterior measure of competition such as $C$ captures these incentives quite well. ${ }^{16}$ In fact, the previously observed effect of $T^{E}$ on mean turnout reduces with the inclusion of $C$, while the effect on turnout variance is no longer significant at conventional levels, indicating that uneven levels of competition usefully help us account for the lower net turnout and higher turnout variability in smaller districts. ${ }^{17}$

\section{Discussion}

The method proposed in this paper to create an index of competition that can be used to estimate incentives for

\footnotetext{
${ }^{16}$ See Cox (1999) for an elaboration of the theoretical argument, and Selb (forthcoming) for cross-national empirical evidence.

17 Our findings may also shed some light on a phenomenon that has long puzzled comparative electoral research: that turnout is higher on average under proportional representation (PR) than in majoritarian electoral systems (e.g. Blais, 2006; Blais and Aarts, 2006), yet turnout may not increase as the number of parties increases. Our findings suggest that lower net turnout in single-member plurality systems may be linked to uneven turnout over districts, which in turn is at least partially a consequence of varying intensities of local-level competition, but that turnout in PR seats may not linearly increase with an increase in district magnitude, and thus may not linearly increase with the number of (effective) parties. We might also note that, in the U.S. and in other first-past the post systems, some districts are highly noncompetitive, and turnout is often low in such districts absent countervailing factors such as the presence of simultaneously held elections of a more competitive nature.
}

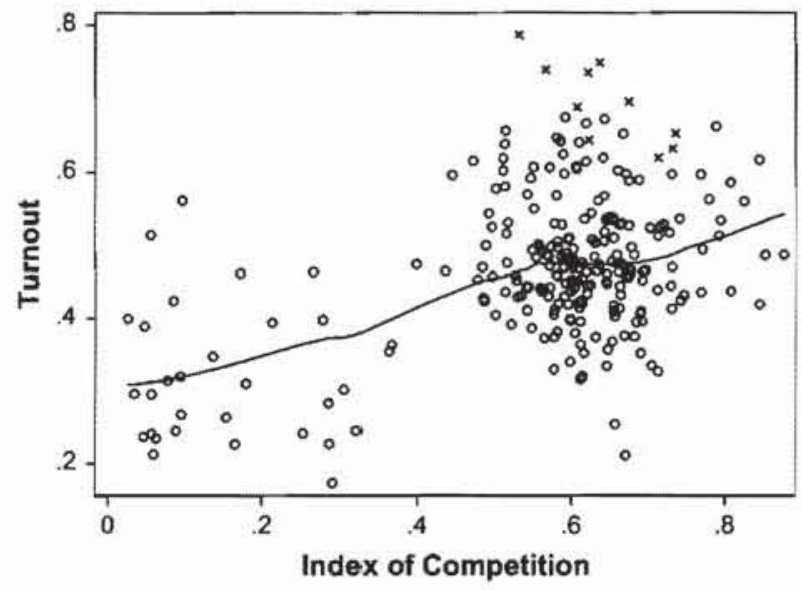

Fig. 2. Turnout versus Index of Competition in Swiss National Council elections, 1971-2007. Note: 253 district-year observations. X's indicate a district (Schafthausen) where voting is compulsory. Line represents locally weighted regression fit (compulsory voting district excluded).

turnout is certainly not the only possible approach. In particular, there are other (closely related) ways to think about incentives for turnout. For example, we might use "best case" instead of "worst case" scenarios. Or, we might use the "best case" scenario for seat gain and the "worst case" scenario for seat loss; or conversely. Or, we might combine "best case" and "worst case" scenarios using some index of optimism-pessimism to weight the two (Luce and Raiffa, 1957). But all of these measures are fundamentally similar to the Index of Competition that we proposed here in that, like that index, they each satisfy the six normative properties we laid out at the start of this article. We believe that those six properties are critical in constructing a fully general index of competition. ${ }^{18}$

Because the population of a, say, an $m$ seat district should be roughly $\mathrm{m}$ times the population of a single seat district, normalizing by the Threshold of Exclusion implicitly takes the parties' calculus to be one of looking at the number of votes needed to gain or lose a seat, rather than at the percentage change in overall vote share in a district needed to gain a seat in that district. If, not implausibly, we believe that parties are more cognizant of percentages than they are of raw votes such a normalization may not seem desirable. For example, treating turnout incentives in an SMD where a hopeless party needs another $40 \%$ to dispute the winner's seat $(c=(0.5-0.4) / 0.5=0.2)$ as identical to the incentives in a 35 -member district where the party needs just another $2.2 \%$ to gain a(nother) seat $(c=(0.28-0.22) / 0.28=0.2)$ may not seem plausible even though $40 \%$ and $2.2 \%$ stand for the same number of voters. Moreover, if one assumes that local party

\footnotetext{
18 There is also the question of whether or not parties make inferences about competition based on current polls or past outcomes. Clearly this is going to be a context specific matter, depending upon the reliability and availability of polling data and the expected volatility of election results. When data is available, either approach may be used in defining Index of Competition values. Which approach is more closely linked to actual turnout is an empirical issue well beyond the scope of this brief note. In our data analysis we used posterior data, but in one of the multivariate models we also added a trend line correction.
} 
organizations are the primary mobilizing agents in districted electoral systems and that the mobilizing capacities of local party organizations is roughly a function of district size, an Index of Competition that expresses mobilization and turnout incentives in relative terms will be a reasonable choice. On the other hand, if we were interested, for example, in how national party organizations distribute campaign expenditures among districts contingent upon their competitiveness, the size of the local electorates probably has to be taken into account.

In an extension of this paper (calculations omitted for space reasons) we have looked at an alternative version of the formulas and calculations given above where there has been no normalization by the Threshold of Exclusion, i.e.,

$c_{i}^{A}=1-2 \times \min \left(x_{i}^{G}, x_{i}^{L}\right)$

Using the non-normalized measure for the Switzerland data eliminates the statistical significance of the Threshold of Exclusion variable in Model 2, and indeed yields a slightly better model fit ( $\chi^{2}$ of 115 as compared to 106 , with 4 d.f.). However, it will have to wait for further data analyses to see which of the two formulations (normalized versus nonnormalized) most consistently captures party and voter incentives and better predicts variation in turnout.

In any case, we must be careful to take population differences across districts of different magnitudes into account when we are aggregating competitiveness levels across districts of different magnitude, say for purposes of cross-country comparisons. As Grofman (2001) points out, if we are interested in the actual number of voters who must change their mind to affect election outcomes, then Threshold of Exclusion values need to be adjusted to take population differences into account across constituencies of different sizes. Within any given country, as we just noted, an $m$ seat district can be expected to have roughly $m$ times the population of a single seat district. Thus, if we are comparing measures of competitiveness aggregated across districts of different sizes then we must further normalize by weighting each district's contribution to the overall competitiveness of (incentives for turnout in) the legislative elections by $m_{j} / S$, where $S$ is the size of the legislature $\left(=\sum m_{j}\right)$. In this fashion we can create an index which is comparable across legislatures. ${ }^{19}$

\footnotetext{
19 Note that such an index is not to be confused with national-level competition indices that use margins of victory between prospective government and opposition parties (e.g. Franklin, 2002). It is rather a more consistent measure of Franklin's (2004) "mean margins of victory across districts" in majoritarian systems (which Franklin globally coded 0 for PR systems). Differences between the Franklin measure and ours are primarily to be expected for "districted proportional representation" systems with relatively small median district magnitudes (see Monroe and Rose, 2002). For Swiss National Council elections 1971-2007 as our empirical case to be introduced below, the national-level Index of Competition $\mathrm{C}$ varies between 0.55 and 0.61 . while Franklin's measure of (non-)competitiveness would have been coded 0 for all the election years. Using Franklin's measure of competition in the same regression as a dummy variable for PR may risk misspecification of the model, especially if most of the cases are ones with PR elections.
}

\section{Appendix}

Table A1

Descriptive statistics of the variables used; 253 observations.

\begin{tabular}{lllll}
\hline & Mean & S.D. & Min & Max \\
\hline District magnitude & 7.85 & 8.222 & 1 & 35 \\
Threshold of Exclusion & .22 & .167 & .028 & .5 \\
Index of Competition & .567 & .174 & .026 & .877 \\
Turnout & .469 & .108 & .174 & .787 \\
\hline
\end{tabular}

Table A2

Bivariate correlations of the variables used; 253 observations.

\begin{tabular}{|c|c|c|c|}
\hline & $\begin{array}{l}\text { District } \\
\text { magnitude }\end{array}$ & $\begin{array}{l}\text { Threshold of } \\
\text { Exclusion }\end{array}$ & $\begin{array}{l}\text { Index of } \\
\text { Competition }\end{array}$ \\
\hline Threshold of Exclusion & $-.695^{* * *}$ & & \\
\hline Index of Competition & $.109^{*}$ & $-.396^{* * *}$ & \\
\hline Turnout & .068 & $-.29^{* * *}$ & $441^{\cdots * *}$ \\
\hline
\end{tabular}

$\cdots p<01: * p<05 ; " p<10$.

\section{References}

Blais, A., 2006. What affects turnout. Annual Review of Political Science 9, $111-125$.

Blais, A., Aarts, K., 2006. Electoral systems and turnout. Acta Politica 44. 180-196.

Blais, A., Robert, Y., Miriam, L., 2000. The calculus of voting: an empirical test. European Journal of Political Research 37, 181-201.

Clarke, H.D., David, S., Marianne, C.S., Paul, W., 2004. Political Choice in Britain. Oxford University Press, London and New York.

Cox, G., 1999. Electoral rules and the calculus of mobilization. Legislative Studies Quarterly 24, 387-419.

Dahl, R.A., Tufte, E.R., 1973. Size and Democracy. Stanford University Press, Stanford, CA.

Downs, A., 1957. An Economic Theory of Democracy. Harper, New York.

Franklin, M.N.. 2002. The Dynamics of Electoral Participation. In: LeDuc, L. Niemi, R.G. Norris, P.(Eds.), Comparing Democracies 2. New Challenges in the Study of Elections and Voting. Sage, London, pp. 148-168.

Franklin, M.N., 2004. Voter Turnout and the Dynamics of Electoral Competition in Established Democracies Since 1945. Cambridge University Press, Cambridge.

Gauglhofer, M., 1988. Analyse der Sitzverteilungsverfahren bei Proportionaiwahlen. Rüegger, Chur.

Grofman, B., 2001. A note of caution in interpreting the Threshold of Exclusion. Electoral Studies 20, 299-303.

Grofman, B., 1993. Is Turnout the Paradox that Ate Rational Choice Theory? In: Grofman, B. (Ed.), Information, Participation and Choice: An Economic Theory of Democracy in Perspective. University of Michigan Press, Ann Arbor, Michigan. pp. 93-103.

Hanks, C.. Grofman, B., 1998. Turnout in gubernatorial and senatorial primary and general elections in the South, 1922-90: a rational choice model of the effects of short-run and long-run electoral competition on tumout. Public Choice 94, 407-421.

Harvey, A.C., 1976. Estimating regression models with multiplicative heteroscedasticity. Econometrica 44, 461-465.

Jacobson, G.C., 1983. The Politics of Congressional Elections. Little, Brown and Company.

Latner, M., unpublished. The ecology of electoral turnout. Ph.D. Dissertation. 2009. Department of Political Science, University of California, Irvine.

Luce, R.D., Raiffa, H. 1957. Games and Decisions. Wiley, New York.

Monroe, B.L. Rose, A.G., 2002. Electoral systems and unimagined consequences: Partisan effects of districted proportional representation. American Journal of Political Science 46, 67-89.

Rae, D. Hanby, V., Loosemore, J. 1971. Thresholds of representation and thresholds of exclusion. An analytical note on electoral systems. Comparative Political Studies 3, 479-488.

Selb, P. A deeper look at the proportionality-turnout nexus. Comparative Political Studies, forthcoming.

Taagepera. R., Grofman, B., 2003. Mapping the indices of seats-votes disproportionality and inter-election volatility. Party Politics 9, 659-677. 